\title{
O BUEN VIVIR COMO PROJETO DE MUNDO CONTRA HEGEMÔNICO ${ }^{1}$
}

\section{THE "BUEN VIVIR" AS COUNTER-HEGEMONIC PROJECT OF WORLD}

\author{
José Luiz Quadros de Magalhães ${ }^{2}$ \\ Sofia Miranda Rabelo ${ }^{3}$ \\ Silvia Gabriel Teixeira ${ }^{4}$
}

\begin{abstract}
Resumo: Este trabalho tem como objetivo abordar a ética do Buen Vivir como um projeto de resistência e como alternativa à compreensão hegemônica de desenvolvimento que tem sido difundido e executado por grandes organizações internacionais e corporações. O Buen Vivir é uma filosofia baseada nas epistemologias do sul, por alguns dos diversos povos originários que foram subalternizados no sistema mundo colonial moderno, conceito que se encontra presente nas constituições plurinacionais do Equador e Bolívia. A partir deste novo principio constitucional andino afirmamos a importância de repensar, segundo uma abordagem decolonial, o papel desempenhado pelos Estados e organismos internacionais nos assuntos relacionados ao desenvolvimento local. A análise crítica da literatura oferece a existência de diferentes visões acerca do desenvolvimento que merecem espaço nos debates acadêmicos e estatais.
\end{abstract}

Palavras chave: Buen Vivir; Capitalismo; Decolonialidade; Desenvolvimento; Novo constitucionalismo.

Abstract: This work is an approach to Good Living Ethics as a project of resistance to the hegemonic model of development that has been disseminated and executed by large international organizations and corporations. The Buen Vivir is a mother based on the epistemologies of the south, subalternizada by more than five centuries of colonization and, at the moment, without movement novo-constitucionalismo Andino. Based on notions, it highlights the importance of rethinking, the second decolonial approach, the role played in the States and static in the themes related to local development. The critical review of the literature provides another insight into what space is in academic and state debates.

Keywords: Capitalism; Decoloniality; Development; Good Living; Neoconstitucionalism.

\footnotetext{
${ }^{1}$ Artigo recebido em 08 de julho de 2019 e aprovado para publicação em 28 de outubro de 2019.

2 Professor do Mestrado e Doutorado da Pontifícia Universidade Católica de Minas Gerais (PUC Minas). Professor da Universidade Federal de Minas Gerais (UFMG). ORCID: https://orcid.org/0000-0003-1366-7122

${ }^{3}$ Professora, doutora em Direito pela Pontifícia Universidade Católica de Minas Gerais (PUC Minas) e mestre em Direito pela Universidade Federal de Minas Gerais (UFMG). ORCID: https://orcid.org/0000-0001-90485977

${ }^{4}$ Professora, mestre e doutoranda pela Universidade Coimbra. ORCID: https://orcid.org/0000-0002-4486-4105
} 


\section{Introdução}

A invasão da América que se inicia ao final do século XV impulsionou a história para uma nova trajetória. O sistema econômico criado pelos europeus, isto é, o capitalismo, deve o ápice de seu desenvolvimento a partir das riquezas extraídas das Américas. Mas esse crescimento só foi possível a partir de um longo processo de extermínio, assassínio, torturas e encobrimentos que perdurou por séculos.

A construção do sistema mundo moderno decorre de rupturas importantes que podem ser sintetizadas por três grandes eventos ocorridos no ano de 1492: o inicio da invasão da América pelos europeus; a expulsão dos muçulmanos e judeus da penísula ibérica e a primeira gramática normativa, a linga aprisionada pelo nascente Estado modereno. Para uma análise do processo moderno tal qual se conhece nos dias atuais é necessário um recorte temporal, e o ano de 1492, nos dizeres de Dussel (1994, p. 7-8) é o auge dos movimentos que deram origem à modernidade, pois é neste ano que se inicia o choque dos europeus com aqueles que não eram seus semelhantes. A modernidade "nasceu no momento em que a Europa pode se confrontar com o "outro" e controlá-lo, vencê-lo, violentá-lo; quando se definiu como um 'ego' descobridor, conquistador, colonizador da alteridade constitutiva da mesma modernidade". É neste ano que "os homens descobriram a totalidade de que fazem parte. Até então, formavam uma parte sem o todo" (TODOROV, 2010, p. 7).

Entretanto, séculos de desenvolvimento econômico acelerado fundado em uma perspectiva moderna indiviudalista e que transforma a natureza em recurso, nos mostra a necessidade de repensar a forma como a relação com o Planeta Terra foi estabelecida neste período de grandes transformações e explorações. É neste instante que o Bem Viver, ou Buen Vivir, ganha visibilidade como uma forte crítica ao modelo capitalista, alertando para a necessidade de mudanças profundas, que superem as visões simplistas que reduziram a sociedade no economicismo. O Bem Viver, como apresenta Acosta (2016), é uma filosofia em construção que parte da cosmologia e do modo de vida, principalmente, dos povos tradicionais da América e tem como significado viver em aprendizado e convivência com a natureza, onde se reconhece que somos parte dela e que não podemos ser seres a parte. "A natureza não está aqui para nos servir, até porque nós, humanos, também somos natureza e, sendo natureza, quando nos desligamos dela e lhe fazemos mal, estamos fazendo mal a nós mesmos" (ACOSTA, 2016, p.15).

Neste mesmo cenário, Boaventura de Souza Santos (2011, p. 26) salienta ser essencial que haja reconhecimento de incompletudes. Entretanto, para que esse caminho seja 
aberto é preciso um trabalho em conjunto, pois além do conhecimento diferente é essencial um processo de criação de conhecimento diferente. A produção de conhecimento deve ser coletiva, participativa e interativa, propiciando um conhecimento-emancipação em detrimento do conhecimento-regulação.

Para tanto, o trabalho irá apresentar o buen vivir como uma compreensão de mundo alternativa e radicalmente diferente do sistema hegemônico instaurado pelo capitalismo, onde se tem como base a solidariedade na vida social como um todo, bem como uma libertação da colonialidade do saber, do ser e do poder. É, conforme Mamani (2010, p. 27), um processo de mudança que insurge na América Latina tendo como base a visão dos povos ancestrais originários que possui potencial para repercutir em todo o mundo.

\section{Da Modernidade à Decolonialidade}

O pensamento ocidental é baseado na separação judaico-cristã entre Deus, o homem e a natureza. Esta teoria defende que Deus criou o mundo, e criou o homem à sua própria imagem e semelhança, elevando-o sobre todas as demais criaturas. A partir disso, tem-se o nascimento do direito de intervenção nos cursos dos acontecimentos da terra/natureza. Em outro momento histórico ocorre uma nova ruptura ontológica entre o corpo e a mente, entre a razão e o mundo na obra de Descartes. Esse rompimento é de suma importância visto que o mundo já não é mais a ordem do significativo. O mundo passa ser apenas um mecanismo desespiritualizado que pode ser tomado pelos conceitos e representações construídos pela razão (LANDER, 2000, p. 5). Este posicionamento tem como herdeiros aspectos específicos de validade que geram a institucionalização do saber, como uma ciência objetiva e uma moral universal e, como consequência, o distanciamento entre a cultura dos especialistas e a cultura do público.

Para a efetivação do poder do Estado são necessárias políticas de homogeneização, de padronização, destacando-se a criação de instituições que propiciam essa homogeneização como o poder central, a moeda nacional, bancos nacionais, exércitos nacionais, a uniformização dos valores e comportamentos com a imposição de uma religião, um idioma nacional oficial (a gramática normativa do castelhano) a escola moderna e um único direito com a gradual uniformização da familia, do direito penal e o direito de propriedade. A identidade nacional, isto é, o sentimento de pertencimento, é um fator imprescindível para a centralização do poder (MAGALHÃES, 2012, p. 17). A construção da identidade se dá a partir da exclusão do outro, do diferente. Esta construção da nacionalidade frequentemente 
ocorre por critérios objetivos como a etnia ou a língua ou a combinação desses fatores adicionados aos fatores de território e história em comum (HOBSBAWN, 1991, p. 15) ${ }^{5}$. A partir dessa visão, será analisado a história da Europa e o surgimento do pensamento moderno, destacando os principais eventos, que irão influenciar toda a humanidade.

Um grande período traumático de violencias e extermínio no continente, chamado pelo invasor de "América", começa com o início da invasão europeia a partir de 1492. A partir do "descobrimento" do "novo mundo" em 1492 por Cristóvão Colombo, os europeus começam o processo de extermínio dos nativos da nova terra ${ }^{6}$. A exploração do novo território fomentou a economia europeia, favorecendo a construção da nova economia moderna: o capitalismo. Durante o período de colonização é perceptível o rebaixamento do outro, independentemente do tipo de colonização sofrida.

De forma diferente da Europa, onde foram construídos Estados nacionais para todos que se enquadrassem ao comportamento religioso imposto pelo poder dos Estados, após a expulsão dos considerados diferentes, na América não se esperava que os indígenas e negros se comportassem como iguais, era melhor que permanecessem à margem, ou mesmo, no caso dos povos originários (chamados de "índios" pelo invasor europeu), que não existissem: milhões foram mortos”. (MAGALHÃES, 2012, p. 25)

A modernidade, a partir desses eventos, começa com o processo de encobrimento do outro $^{7}$. Confirmando com a ideia do eurocentrismo, possuía-se um mundo conhecido e conforme configuração global, localizado no centro do mundo e um mundo separado entre África, Europa e Ásia (Índias) (DUSSEL, 1994, p. 29). Assim a Europa passa a ser entendida como o único lugar possível para a existência da racionalidade humana, tendo em vista ser o local onde se encontrava a fórmula para os seres considerados perfeitos (homens, brancos, cristãos e ocidentais) (SILVA, 2014, p. 40). A separação entre corpo e mente proposta pela filosofia moderna torna-se fundamental para a justificativa da escravidão, do extermínio, da exploração e da tortura. Existem corpos sem razão, corpos sem alma. A compreensão da

\footnotetext{
${ }^{5}$ Faz-se aqui um destaque para o conceito de epistemicídio apresentado por Boaventura de Souza Santos (2009, p. 10) que consiste na "supressão dos conhecimentos locais perpetrada por um conhecimento alienígena", isto é, foi suprimido todas as práticas sociais de conhecimentos que contrariassem os interesses da colonização, sendo assim necessário uma 'missão colonizadora', como projeto com o objetivo de homogeneizar o mundo, destruindo progressivamente as diferenças culturais.

${ }^{6}$ Conforme SILVA (2014), “a conquista da América, portanto, pode ser vista como afirmação prática dos ideais da modernidade, do poder de imposição de um modelo sobre qualquer outro que lhe seja diverso. É a negação do diferente enquanto diferente, do outro enquanto ser racional, detentor de personalidade, de uma sociabilidade de culturas próprias" (p. 42).

7 “A modernidade enquanto história humana é o momento em que o Homem europeu, branco, ocidental e cristão, assume o papel de verdadeiro paradigma, por onde só poderiam ser considerados Homens, aqueles que cumprissem a cartilha europeia de ser" (SILVA, 2014, p. 39).
} 
Europa como o espaço da civilização do homem branco racional o construtor da grande civilização hegemônica, que tem por missão civilizar todo o restante da humanidade cria as bases para um falso universalismo, um falso universalismo europeu que fundamenta, até hoje, na crise final do sistema mundo colonial moderno, a imposição de modelos e sistema economicos, políticos e sociais, fundados em uma forma universalizada pela força, dos valores, compreensões e interesses europeus.

Verifica-se hoje a grande dificuldade, dentro da política e das ciências sociais, em apresentar alternativas teóricas e práticas para a grave crise do sistema mundo moderno, tendo em vista a dominação cultural e econômica expressas pela hegemonia das compreensões teóricas e cientificas do mundo branco europeu. O cenário onde o neoliberalismo é debatido e confrontado como uma teoria econômica no lugar de analisar a realidade como um discurso hegemônico de um modelo civilizatório. Daí a enorme dificultade de pensar e construir alternativas $^{8}$. Há um aprisionamento do pensar em referências e gramaticas modernas, propositalmente congeladas, como congelados foram os idiomas oficias a partir do castelhano. Como bem salienta Lander:

(...) las alternativas a las propuestas neoliberales y al modelo de vida que representan, no pueden buscarse en otros modelos o teorías en el campo de la economía ya que la economía misma como disciplina científica asume, en lo fundamental, la cosmovisión liberal. (2000, p. 4)

A construção de novos caminhos exige a desconstrução do caráter universal e natural da sociedade capitalista liberal. Para tanto é preciso questionar os instrumentos de naturalização e legitimação dessa ordem. É necessário dar voz aos conhecimentos que a muito lutam para sobreviver em todas as partes do mundo que muito tem a contribuir para a construção desse novo paradigma de mundo. Como bem salienta Boaventura de Souza Santos e Maria Paula Menezes:

Por um lado, o capitalismo global, mais que um modo de produção, é hoje um
regime cultural e civilizacional, portanto, estende cada vez mais os seus tentáculos a
domínios que dificilmente se concebem como capitalistas, da família à religião, da
gestão do tempo à capacidade de concentração, da concepção de tempo livre às
relações com os que nos estão mais próximos, da avaliação do mérito científico à
avaliação moral dos comportamentos que nos afectam. Lutar contra uma dominação
cada vez mais polifacetada significa preversamente lutar contra a indefinição entre
quem domina e quem é dominado, e, muitas vezes, lutar contra nós próprios. Por
outro lado, a resiliência do capitalismo revelou-se na reiterada operacionalidade de

\footnotetext{
${ }^{8}$ No período pós Guerra é apresentado, dentro das Ciências Sociais, a teoria da modernização com o objetivo de explicar o desenvolvimento. É proposto um processo de transição das "sociedades tradicionais" para a "sociedade moderna", um movimento considerado desejável. Para tanto seria preciso à transformação da organização tradicional em burocracias fundadas nos princípios do liberalismo (LITTLE, 2002, p. 34).
} 
uma das suas armas que parecia ter sido historicamente neutralizada: o colonialismo. (2009, p. 10)

Catherine Walsh (2008) ao analisar esse contexto aponta quatro formas de percepção da colonialidade. O primeiro seria a colonialidade do poder, onde se destaca o estabelecimento de hierarquia social a partir de critérios raciais e sexuais e uma ordem de superioridade (em ordem decrescente: homens brancos, mestiços, indígenas e negros). Essa classificação é utilizada como justificativa para exploração de mão de obra dos menos favorecidos. Nos dias atuais é base para a negativa de políticas compensatórias.

Outro ponto apresentado é a colonialidade do saber responsável pela propagação da visão eurocêntrica nas searas epistemológicas e científicas. A partir de então se observa a desqualificação de outros saberes fundados em matrizes culturais diversos (WALSH, 2008).

Já a colonialidade do ser é a desvalorização e a desumanização dos que distanciamse do padrão eurocêntrico de racionalidade e etnicidade. E por último a colonialidade da mãe natureza e da vida em si que irá reproduzir a separação entre os seres humanos e a natureza, transformando uma relação ancestral em uma visão meramente orgânica e material. De acordo com Walsh,

Al negar esta relación milenaria, espiritual e integral, explotar y controlar la naturaleza y resaltar el poder del individuo moderno civilizado (que aún se piensa con relación al blanco europeo o norteamericano) [...] la colonialidad ha pretendido acabar con todo la base de vida de los pueblos ancestrales (2008, p. 139)

Evidencia-se que a colonialidade da natureza além de ser fundamento para a sociedade mercantilista capitalista, é fundamental para a construção dos discursos hegemônicos e excludentes.

La colonialidad de la naturaleza, tal vez va más allá de la colonización de ésta, deberá entenderse como la manera en que se construyen discursos hegemonizantes y excluyentes con respecto a quienes tienen el derecho de conocerla y explotarla, de protegerla y resguardarla. Tal vez en la irracionalidad de la racionalidad occidental, como lo ha planteado Dussel (2001), no cabe hoy en día admitir la presencia de pueblos enteros que se niegan a relacionarse con el mundo natural agredido por la avalancha tecnológica, desde su reducción a la posibilidad de ser solamente una mercancía más (ALBÁN; ROSERO, 2016, p.30).

A partir final do século XX, a comunicação global em tempo real, os processos de resistencia e luta por direitos em comunicação pelo globo, permitem um momento importante de desocultamento. A falsa homogeneidade dos estados modernos é contraposta pela visibilidade cada vez maior de uma impressionante diversidade étnica, linguisticas, uma diversidade de compreensões de mundo, de espiritualidades, de gramáticas e desejos. No âmbito do direito internacional destaca-se o reconhecimento obtido na Convenção 169 da 
Organização Internacional do Trabalho que reconhece as aspirações dos povos em assumir o controle de suas próprias instituições, formas de vida e desenvolvimento.

$\mathrm{Na}$ América Latina esse movimento chega ao poder, lentamente, ocupando espaços nos textos constitucionais, desafiando as teorias constitucionais modernas até as importantes e potencialmente revolucionarias cosntituições plurinacionais do Equador e Bolívia em 20018 e 2009. Estes novos processos constituintes repercutem em outros estados americanos e desafiam as compreensões e jurisprudenciais modernas europeias antropocentrica e desenvolvimentistas. Não se trata, portanto, apenas de elaborar novos projetos de desenvolvimento que superem as pretensões universalistas e a ideologia neoliberal (LITTLE, 2002, p. 36) ${ }^{9}$, mas de questionar a própria essência da ideia de crescimento e desenvolvimento ou sua radical ressignificação.

O etnodesenvolvimento pode ser compreendido como desenvolvimento econômico de um grupo étnico e/ou ${ }^{10} \mathrm{de}$ um grupo social. O etnodesenvolvimento introduz novos temas ao espaço público, já no aspecto político irá apresentar um recorte étnico sobre a autodeterminação dos povos e noções de excludentes de soberania nacional. No âmbito econômico o etnodesenvolvimento tem o objetivo de apresentar-se como alternativas econômicas, onde a ideologia neoliberal é predominante (LITTLE, 2002, p. 40). É sempre importante o cuidado com o que podemos chamar de armadilhas da modernidade, ou, em outras palavras, apenas renomear o velho e suas praticas, oferecendo uma ropagem nova. As armadilhas modernas são muitas, e para não cairmos em seus desvios é necessário ter claro os conceitos de coloniadade do ser, do saber e poder, já mencionados anteriormente. Dentro desta perspectiva, o buen vivir apresenta-se como um projeto contra hegemônico de transformação economica, liberto dos conceitos modernos de crescimento, desenvolvimento, quantidade, melhor e pior. Viver bem não é viver melhor. Não é a busca incansável de prosperidade, crescimento e desenvolvimento. Exclui-se da percepção do "bem viver" a deseperadora e constante busca de viver melhor. O que se busca é o equilibrio, o viver bem, em uma perspectiva de integralidade. Complementaridade, em uma percpção da vida e natureza enquanto um sistema: um ecosistema. Ecosistemas dentro de ecosistemas.

\footnotetext{
9 Ressalta-se que as reivindicações promovidas pelos povos originários da América Latina não devem ser interpretados como uma ameaça à soberania dos Estados, ou como movimentos separatistas. O objetivo é ganhar autonomia sobre as decisões que os afetam diretamente. Logo é participar do controle de decisões sobre os recursos naturais existentes em seus territórios e recursos culturais (LITTLE, 2002, p. 40-41).

${ }^{10}$ Não são entendimentos excludentes.
} 


\section{O Buen Vivir}

O primeiro passo para a construção desse novo mundo contra hegemônico é nomeadamente o reconhecimento da diversidade epistemológica, gerando condições para um diálogo horizontal entre os saberes. O Buen Vivir apresenta-se como um projeto de resistência/alternativa ao modelo hegemônico de desenvolvimento. Conforme Mignolo (2005)

o Buen Vivir pode ser explicado como uma manifestação decolonial epistêmica, um pensamento que abre oportunidades até então encobertas pelo eurocentrismo.

A decolonialidade apresenta-se como uma alternativa ao sistema-mundo capitalista/patriarcal/cristão/moderno/colonial europeu que surge com a modernidade, e conforme o marco temporal apresentado por Dussel (1993), 1492 é o seu marco simbólico de inicio. Não é possível entender o desenvolvimento europeu, que ocorre nos períodos das revoluções, sem compreender o papel fundamental da construção do sistema mundo colonial, com a exploração sistemática das riquezas naturais, dos saberes e trabalho dos povos e de seus territórios colonizados.

O projeto decolonial tem como objetivo principal não mais submeter à subalternização de poder/saber, visa libertar os povos colonizados de uma forma imposta pelo colonizador de ver, compreender e sentir mundo. A libertação da coloniadade do ser e do poder tornará a libertação das outras formas coloniais de exploração, inevitável. A avalanche decolonial não poderá ser evitada pelos mecanismos de controle e subalternização criados pelo sistema mundo moderno europeu. Trata-se da superação de um sistema de poder imposto pelo capitalismo, construído como sistema econômico moderno global, pelos países além da linha abissal ${ }^{11}$. É apresentada uma nova perspectiva para o progresso e desenvolvimento, um novo olhar para o mundo a partir do Bem Viver.

De acordo com Gudynas (2015) é uma reação aos conceitos tradicionais de desenvolvimento, onde se permite ter três planos de abordagem: ideias, discursos e práticas. No plano das ideias serão apresentados questionamentos radicais às bases conceituais do desenvolvimento, principalmente nos aspectos de ideologia do progresso. Os discursos referem-se à legitimação das ideias, pois o bem viver discorda que o crescimento econômico

${ }^{11}$ O pensamento abissal é apresentado por Boaventura de Souza Santos (2007, p. 3-4) como o pensamento moderno ocidental que possui um sistema de distinções visíveis e invisíveis, "sendo que as invisíveis fundamentam as visíveis. As distinções invisíveis são estabelecidas através de linhas radicais que dividem a realidade social em dois universos distintos: o uni verso "deste lado da linha" e o universo "do outro lado da linha”. (...) A característica fundamental do pensamento abissal é a impossibilidade da co-presença dos dois lados da linha. Este lado da linha só prevalece na medida em que esgota o campo da realidade relevante. Para além dela há apenas inexistência, invisibilidade e ausência não-dialéctica”. 
ou o consumo material são basilares para indicadores de bem estar. Já as ações práticas são o campo de maior desafio para o Buen Vivir, pois devem ser apresentados projetos políticos viáveis de mudança, planos governamentais e legislações pertinentes sem repetir as posturas convencionais tão criticadas. Poderiamos dizer aqui, que o "bem viver" é um conceito que extrapola os conceitos modernos de projetos políticos e políticas públicas estatais. Tentar aprisioná-los dentro destes conceitos pode ser a sua destruição. Este é o desafio. O sentido de "bem viver" não é moderno. Aprisioná-lo em um sistema estatal moderno pode ser o seu comprometimento total. Este é o perigo do que chamamos de "armadilhas modernas". Construir o bem viver por meio de políticas públicas estatais é viável? Este seria o caminho? Ou o bem viver implica no fim dos aparatos, aparelhos, estruturas de poder modernas?

Neste sentido Acosta (2011) faz o convite para que imaginemos outro mundo, uma transformação deste a partir de um "desenvolvimento" diferente, incentivado pelos direitos humanos e que tenha como base o reconhecimento do Direito da Natureza, base de uma economia solidária. Acosta faz a seguinte provocação:

La pregunta que cabe, a este punto, es si será posible y realista intentar un desarrollo diferente dentro del capitalismo. Se entiende por diferente, un desarrollo impulsado por la vigencia de los derechos humanos (políticos, sociales, culturales, económicos) e los novísimos derechos de la naturaleza como base de una economía solidaria. ¿Seguirá siendo el acaso desarrollo un fantasma que nos continúe atormentando o una utopia que nos oriente? Es más ¿será necesario superar el concepto de desarrollo y adentrarmos en una nueva epoca, la del postdesarrollo? (ACOSTA, 2011, p. 189).

O Buen Vivir tem origem nos povos ancestrais andinos, originalmente denominados de Suma Quamaña em Aymara, Sumak Kawsay em Quéchua (MAMANI, 2010), Kume Mogen em Mapuche e Teko Kavi em Guarani (ESTERMANN, 2013) e tem como significado o viver pleno ou viver plenamente, em uma conceituação mais ampla. Dentro da literatura, alguns autores (ESCOBAR, 2010; ESTERMANN, 2013) referem-se Vivir Bien como sinônimo de Buen Vivir e aos termos Vivir Bien e bienestar (ACOSTA, 2008).

Os estudos sobre o tema ganham visibilidade cada vez maior e o buen vivir pode ser considerado um caminho, uma orientação, que se apresenta como alternativa ao modelo hegemônico europeu, uniformizado. “Bem viver” não é um conceito fechado. Não pode ser. É uma abertura para outros saberes, outros sentidos, plurais, complementares, diversos. Nos dizeres de Boaventura (2006, p. 397) “(...) é a resistência transnacional organizada contra as trocas desiguais produzidas ou intensificadas por localismos globalizados ${ }^{12}$ e globalismos

${ }^{12}$ De acordo com Boaventura (1997, p. 16) "consiste no processo pelo qual determinado fenômeno local é globalizado com sucesso, seja a atividade mundial das multinacionais, a transformação da língua inglesa em 
localizados ${ }^{13}$ ". O Buen Vivir questiona os conhecimentos considerados como 'verdades' impostos pelo eurocentrismo universalizante.

Nos dizeres de Mamani (2010, p. 27) o buen vivir é

El paradigma comunitario de la cultura de La vida para Vivir Bien: sustentado en una forma de vivir plasmada en la práctica cotidiana del respeto, de la relación armónica y el equilíbrio con todo lo que existe, comprendiendo que en la vida todo está integrado, conectado, es interdependiente y esta profundamente interrelacionado.

A partir de um ponto de vista multiverso apresenta possibilidade para compreender, explicar e viver o mundo onde é basilar o conhecimento do inter-relacionamento entre tudo que existe na Terra, pois equilíbrio e harmonia são essenciais para a sociedade. Rompe-se com modelo antropocentrista e cartesiano que prevalece nos dias atuais, onde o ser humano é referencia dominante de vida, por ser o único ser com capacidade subjetiva ativa e passiva para contrair obrigações.

Destaca-se que este projeto envolve política, economia, culturas e soiedade (MAMANI, 2010). Dussel e Ibarra-Colado (2006) destacam que ideia de pluriverso cria a possiblidade da diversidade cultural ser abrangida, preservando as identidades e, principalmente, a capacidade de escolher os benefícios da modernidade no que se refere a meios de produção, organização social, projetos educacionais e saúde. É o pensamento crítico da epistemologia do sul $^{14}$, pois não se defende a exclusão de todo o conhecimento produzido até o momento, mas este deve ser visto com um olhar analítico do sul.

No ponto de vista econômico, Acosta (2010) lembra que o desenvolvimento é pautado no processo de construção contínuo e reproduzível de benefícios sociais, assim a noção de pobreza não é associada a carência de bens materiais. Neste contexto as relações de produção visam a qualidade e suficiência da sociedade, distanciando-se da ética de acumulação de bens materiais. É preciso frisar que não se intenta a construção de um Estado

língua franca, a globalização do fast food americano ou da sua música popular, ou a adoção mundial das leis de propriedade industrial ou telecomunicações dos EUA".

${ }^{13}$ Boaventura (1997, p. 16) define globalismo localizado como "impacto específicos de práticas imperativos transnacionais nas condições sociais, as quais são, por essa via, desestruturadas e reestruturadas de modo a responder a esses imperativos transnacionais".

${ }^{14}$ A ideia aqui abarcada é o Boaventura (2009, p. 12) chamada de epistemologia do Sul, onde "o sul aqui é concebido metaforicamente como um campo de desafios epistêmicos, que procuram reparar os danos e impactos historicamente causados pelo capitalismo na sua relação colonial com o mundo. Esta concepção de Sul sobrepõe-se em parte com o Sul geográfico, o conjunto de países e regiões do mundo que foram submetidos ao colonialismo europeu e que, com exceção da Austrália e da Nova Zelândia, não atingiram níveis de desenvolvimento econômico semelhante ao do Norte global (Europa e América do Norte). (...) As epistemologias do Sul são o conjunto de intervenções epistemológicas que denunciam essa supressão, valorizam os saberes que resistiram com êxito e investigam as condições de um diálogo horizontal entre conhecimentos". 
controlador, mas sim criar meios para que a sociedade não seja governada pelo mercado global capitalista. Desta forma, o grande desafio desse projeto contra hegemônico é sua implementação e a instrumentalização dessas políticas. Desta maneira,

el desarrollo desde la propuesta del Vivir Bien, se analiza en su sentido sistémico, integrador e dinâmico, que implica un diálogo de saberes de las culturas ancestrales con las actuales culturas, respeto la diversidad, convivência armónica entre seres humanos y entre estos y la naturaleza (ACOSTA; GUDYNAS, 2011, 288).

Mamani (2010) destaca o papel organizacional a ser exercido pela economia comunitária complementar. A nova dinâmica de produção e distribuição de produtos deve ser baseada na equiparação do homem e da natureza como sujeito de direitos. Seguindo o conhecimento ancestral andino, a comunidade representa uma economia sem fins exclusivos de acumulação de capital, a produção age em prol do equilíbrio da vida de todos, já que são partes de uma unidade. $\mathrm{O}$ "desenvolvimento" reconhece a inexistência de hierarquia entre as necessidades do homem e da natureza. $\mathrm{O}$ autor ainda frisa a estrutura educacional do Buen Vivir onde visa à emancipação epistemológica, libertando o homem do pensamento dominante ocidental.

Frente às modificações que vem ocorrendo no meio ambiente do planeta, como as mudanças climáticas e suas consequências, abre-se o alerta para a humanidade sobre os riscos, ecológicos e sociais, para a sobrevivência dos seres vivos. É neste cenário que Amartya Sen (2010) ensina que crescimento econômico não é sinônimo de desenvolvimento e que não deveria ser o único caminho para se alcançar este. E como forma de comprovação destaca que nunca foi visto, como nas últimas décadas, uma abundância de produção e ao mesmo tempo a persistência da pobreza, fome e desnutrição, bem como ameaças ao meio ambiente e a sustentabilidade da vida econômica e social. Logo, a ideia de inesgotabilidade dos recursos naturais é irreal. Sendo preciso, é urgente a mudança da lógica de desenvolvimento apresentada até agora como única.

O buen vivir, conforme destaca Acosta (2011), apresenta-se como uma filosofia a questionar o conceito de desenvolvimento, fundado na ideia moderna de que progresso e o futuro são condicionantes a partir da existência de acumulação de bens, através de um desenvolvimento sustentável, uma etapa de mudança de paradigma capitalista. Importante lembrar que direito da natureza não é sinonimo de direito ambiental. A perspectiva do direito da natureza é ecocentrica e, logo, não compreende o ser humano como individuo racional, dissociado da natureza, mas como parte inseparável desta. O Direito Ambiental é moderno, antropocentrico e vinculado à ideia moderna de individualismo, sustentando que a natureza, 
enquanto recurso, existe para suprir as necessidades do ser humano. O direito ambiental trabalha com a ideia de desenvolvimento sustentável, o que implica na manutenção de pressupostos moderno como, crescimento, separação indivíduo e natureza, economia moderna capitalista, sociedade de consumo, progresso e desenvolvimento. $\mathrm{O}$ acumulo permanente de bens não tem futuro.

O buen vivir tem como objetivo suscitar a busca por opções de vida boa que não seja apenas o modo de vida ocidental de vida melhor. É uma nova perspectiva proposta por meio de uma nova arquitetura conceitual onde há uma vida equilibrada entre os indivíduos e a coletividade, com a sociedade e a natureza. Assim, destaca Acosta (2011, p. 194)

(...) Con la consolidación del capitalismo que produjo el divorcio entre economía y naturaleza, se instrumentó al ser humano, a la sociedad y la misma naturaleza como simples herramientas de producción. Eso se replica en las políticas sociales donde se habla de usuarios e incluso de clientes de las mismas, eliminando la característica básica sobre la que deberían desarrollarse: la ciudadanía con derechos y deberes en contexto colectivo. La lista de conceptos y palabras manipuladas es enorme; por ello es necesario recuperar la soberanía conceptual.

Com esses questionamentos sobre desenvolvimento apresentados pelo buen vivir a natureza passa a apresentar-se no centro dos debates, uma vez que esta não pode ser vista apenas como uma condição para o crescimento econômico ou mero objeto de políticas de desenvolvimento, mas sim como um sistema complemetar, integral, em que o ser humano se realize em comunidade, com os demais seres humanos e com todas as outras formas de vida que integram o seu ecosistema, sem o intuito de dominar a natureza. Lembremos a frase de Acosta (2011, p. 195): "la humanidad no está fuera de la natureleza". Não mais se pode entender a natureza como algo que deve ser dominado e explorado, apenas um 'capital natural'. É preciso uma nova ética para organizar a vida.

Essa transformação também afeta radicalmente a compreensão dos Direitos Humanos, conceito moderno que muda sob a ótica do buen vivir. Desde sua concepção o ser humano foi considerado centro no estabelecimento de direitos. Toda a estrutura normativa dos Direitos Humanos tem como objetivo principal o ser humano. Nos direitos de primeira e segunda geração, isto é, reconhecimento da cidadania é vista apenas pelo ponto de vista individualista da cidadania. Já nos direitos de terceira geração, os direitos econômicos, culturais e ambientais estão previstos que todos os seres humanos têm o direito a ter um ambiente saudável e condições sociais equitativas. Os direitos de terceira geração têm como característica principal, portanto, uma justiça ambiental que tem objeto principal de proteção à 
população pobre e marginalizada, pois preza-se pela qualidade de vida e condições de vida, sendo possível indenização pelos danos ambientais causados.

Porém quando se apresenta o direito da natureza o centro é voltado para a natureza, sendo sua importância tão grande por si só, não relacionada apenas a sua utilidade para os seres humanos, que são também parte da natureza. Há assim uma ecocentrica, onde o foco deslocasse para a compreensão de ecossistemas equilibrados, que para viver dependem deste equilibrio, ou seja, das interações constantes entre todos os seres vivos, de ecosistemas que integram outraos ecossistemas e assim em diante. A perspectiva ecocentrica tem como o objetivo assegurar a persistência e a sobrevivência das espécies nos ecossistemas, pois são redes de vida (ACOSTA, 2011, p. 199). E é com esse olhar que os textos constitucionais equatorianos e bolivianos são editados e entram em vigor em seus territórios. Refundam-se seus Estados com o buen vivir como filosofia a ser praticada e que se pode espelhar e espalhar para toda a comunidade internacional a fim de construir-se um novo mundo.

\section{Os novos textos constitucionais bolivianos e equatorianos e a influência do Buen Vivir}

As grandes transformações e movimentações sociais e políticas que levaram aos processos constituintes na Bolívia e Equador ultrapassaram a "alienação do lugar", isto é, da reflexão e instrumentalização dos espaços a partir de necessidades que lhes são estranhas (SANTOS, 2014, p. 80), e passaram a uma reflexão interna, sobre seus próprios rumos, com o objetivo de viabilizar o resgate da cultura e das cosmologias tradicionais. Esse processo culminou na elaboração de novas constituições, Equador em 2008 e na Bolívia em 2009. Através de movimentos democráticos participativos e populares radicais fundam um novo Estado que deve buscar a superação da brutalidade dos Estados nacionais nos seus processos constantes de homogeneização e exclusão do outro não adaptado ao modelo hegemônico. Os Estados são agora Estados Plurinacionais, com bases democráticas comunitárias diversas, plurais e populares.

Este processo de construção de um novo constitucionalismo muitos autores e estudiosos do tema chamam de "Novo Constitucionalismo democrático latinoamericano" que nada tem em comum com o chamado "neoconstitucionalismo" de base europeia. A consagração do "novo constitucionslismo" pode ser vista nos textos constitucionais da Bolívia e Equador ao estabelecer o Estado Plurinacional, onde é reconhecida a democracia participativa e economia conforme os valores tradicionais dos diversos grupos étnicos e culturais existentes em seus territórios. O Novo Constitucionalismo Latino Americano é 
apresentado por Viciano e Martínez (2010, p. 26) como modelo teórico prático. Segundo Walsh (2008, p. 143), “ambas as Cartas desestabilizan la hegemonía de la lógica, dominio y racionalidad occidentales", uma vez que há a superação da noção tradicional de Estado Social que teve sua origem na segunda metade do séc. XX, introduzindo a garantia de um Estado de bem-viver.

A segurança constitucional é fundada na ideia de que a Constituiçaõ deve ser tão forte e duradoura que apenas um poder social mais forte, representando a força democrática de uma vontade histórica do povo, pode romper para a criação de uma nova Constituição. É preciso destacar que apenas processos democráticos dialógicos que contenham forte mobilização popular são justificativas para uma ruptura, uma vez que sendo um fato irresistível irá se afirmar com força, mas não ilimitada. Observa-se, assim, que o Direito não se encontra apenas no texto positivado, mas também, e principalmente, na ideia de justiça dialogicamente compartilhada em processos democráticos de transformação social e terá como consequência a capacidade de legitimar o Direito e suas transformações e rupturas constitucionais (MAGALHÃES, 2009).

Neste processo de refundação dos estados observa-se a influencia do pluralismo, pois a preocupação com diversidade social faz com que o texto constitucional reconheça a noção de Estado Plurinacional, superando-se assim o modelo moderno e europeu de Estado Nação. O Estado Plurinacional reconhece que na formação de um Estado encontram-se uma pluralidade de nações e culturas diferentes, que exigem políticas estatais sob o prisma da interculturalidade (MELO; BURCKART, 2018, p. 9).

Para Magalhães (2012, p. 29) o Estado Plurinacional tem como base a democracia consensual, dialógica e participativa que permitem superar as bases uniformizadoras e intolerantes do Estado Nacional. Portanto rompe-se com as bases teóricas e sociais do Estado nacional constitucional e democrático representativo.

É necessário destacar que a plurinacionalidade não se resume apenas ao reconhecimento dos direitos políticos dos povos originários e sua vinculação ao Estado. A plurinacionalidade implica na existencia do pluralismo jurídico horizontal; no pluralismo espistemológico; em uma justiça de mediação e uma democracia dialógica consensual. Tratase da afirmação pública da vontade de incorporar novos olhares e percepções sobre a relação das sociedades e a natureza. O reconhecimento dos povos originários como sujeitos de direitos por título próprio faz com que sua visão seja conhecida, oferecendo-se uma postura 
mais favorável aos direitos de todos. Também significa a relevância constitucional da cultura dos novos sujeitos (CLAVERO, 2015, p. 117-118).

As novas constituições para contemplar todas essas mudanças são mais amplas, complexas e detalhadas ${ }^{15}$ abordando suas realidades plurais, trazendo a afirmação do bem viver, defendido pelos povos tradicionais e fundamentadas nas experiências comunitárias, que permitirão a reconstrução das identidades culturais e heranças ancestrais (WOLKMER, 2012, 51-69). Observa-se a partir dessa mudança de paradigma uma refundação do Estado com novas bases, onde é atribuído um valor essencial à biodiversidade e à sociodiversidade, que passam a ser reconhecidas nos textos constitucionais como bens da comunidade e das coletividades. É, portanto, uma grande e importante inovação para a teoria da constituição ao incluir princípios das cosmovisões indígenas, responsáveis por conceber os recursos e a própria estrutura social como bens comuns e expressões da Pachamama (MELO, 2013, p. 74$84)$.

Boaventura Santos (1998) destaca que essa refundação do Estado se dá a partir do que a sociologia chama de sociologia das ausências ${ }^{16}$ e sociologia das emergências ${ }^{17}$, isto é, nasce a partir do momento que grupos sociais tomam ciência de sua condição de exclusão dentro do contexto político de seu país e se coloca em movimento para alterar e construir uma nova sociedade, com novas práticas e novos saberes. É neste momento que há a comprovação que o constitucionalismo não nasce democrático e que as democracias representativas modernas limitam as escolhas em detrimento da segurança jurídica, busca primordial do constitucionalismo moderno europeu, segundo proposto por José Luiz Quadros Magalhães (2010, p. 10) e que na América Latina há uma evolução e uma positivação de novos direitos, uma vez que,

Cuando los movimientos indígenas, en el continente latinoamericano y en el mundo levantan la bandera de la refundación del Estado, lo hacen por haber sufrido históricamente - y por seguir sufriendo hoy en día - las consecuencias de todas las

\footnotetext{
${ }^{15}$ A Constituição Boliviana possui 411 artigos, enquanto a Constituição Equatoriana contém 444 artigos.

16 "Por sociologia das ausências entendo a investigação que tem por objetivo mostrar que o que não existe é, em efeito, ativamente produzido como não-existente, ou seja, como uma alternativa não crível ao que existe. Seu objeto empírico é impossível desde o ponto de vista das ciências sociais convencionais. Trata-se de transformar objetos impossíveis em objetos possíveis, objetos ausentes em objetos presentes. A não-existência é produzida sempre que uma certa entidade é desqualificada, considerada invisível, não inteligível ou descartável. Não há, por isso, uma só maneira de produzir ausência, mas várias. O que as une é uma mesma racionalidade monocultural. Distingo cinco modos de produção de ausência e não-existência : o ignorante, o atrasado, o inferior, o local ou particular e o improdutivo ou estéril" (SANTOS, 1998, p.37) (tradução nossa).

17 "consiste em substituir o vazio do futuro segundo o tempo linear (um vazio que tanto é tudo como nada)" e substituir esse vazio "por um futuro de possibilidades plurais e concretas, simultaneamente utópicas e realistas, que se constroem no presente a partir das atividades de cuidado" (SANTOS, 1998, p. 40) (tradução nossa).
} 
características [...] del Estado moderno en muchas de sus metamorfosis (en el continente, en especial, el Estado colonial, el Estado liberal, el Estado desarrollista, el Estado burocrático y el Estado de mercado. (SANTOS, 1998, p. 70).

Uma importante inovação prevista nos textos constitucionais são as formas de poder popular e accountability social ${ }^{18}$ onde fortalece os povos e comunidades indígenas por meio de um controle democrático do exercício de poder, dando origem ao poder ciudadano na Venezuela, e várias outras formas controle dos povos e movimentos sobre o poder do Estado na Bolívia e no Equador Estes por sua vez superam a tripartição do poder proposta por Montesquieu (1994) e garante a sociedade a possibilidade de ratificação, através de referendo e atos da vida politica, a participação pratica e efetiva da política estatal.

Nos dizeres de Magalhães (2009):

\begin{abstract}
A América Latina (melhor agora a América Plural), que nasce renovada nestas democracias dialógicas populares, se redescobre também indígena, democrática, economicamente igualitária e socialmente e culturalmente diversa, plural. Em meio à crise econômica e ambiental global, que anuncia o fim de uma época de violências, fundada no egoísmo e na competição a nossa América anuncia finalmente algo de novo, democrático e tolerante, capaz de romper com a intolerância unificadora e violenta de quinhentos anos de Estado nacional.
\end{abstract}

$\mathrm{Na}$ Constituição Boliviana a questão indígena é abordada em aproximadamente 80 (oitenta) artigos. Ficou estabelecido no texto constitucional que os 36 povos originários passam a ter direito de participação ampla e efetiva em todas as esferas de poder, bem como na economia. Foi estabelecida uma cota de parlamentares proveniente dos povos indígenas. Além da descentralização das normas eleitorais, onde os povos indígenas poderão ser eleitos a partir das normas eleitorais de sua própria comunidade (MAGALHÃES, 2012, p. 29-30). A Bolívia, por exemplo, colocou em prática as normas que determinavam a inclusão dos saberes tradicionais nas grades escolares.

A nova constituição também estabeleceu a criação um Tribunal Constitucional plurinacional, onde seus membros são eleitos pelo sistema ordinário e pelo sistema indígena. Outra importante modificação é a organização territorial do país que passa a ter quatro níveis de autonomia: o departamental (semelhante aos estados no Brasil), o regional, o municipal e o indígena. Cada região autônoma pode promover eleições diretas de seus governantes, além de administrar seus recursos econômicos. Outra importante modificação foi em transformar o

18 Robl Filho (2013, p. 35) apresenta a seguinte definição: "estruturalmente, accountability significa a necessidade de uma pessoa física ou jurídica que recebeu uma atribuição ou delegação de poderes prestar informações e justificações sobre suas ações e seus resultados, podendo ser sancionada política e/ou juridicamente pelas suas atividades. Nesse sentido, entende-se por accoutability social o controle por parte do povo das ações de seus governantes, bem como a sua possibilidade de interferência e deslegitimação" 
Estado Boliviano em um Estado Laico, pois a religião católica ainda era a oficial. Além de reconhecer as variadas formas de família (MAGALHÃES, 2009).

O Equador é um Estado constitucional de direito e justiça, social, democrático, soberano, independente, unitário, intercultural, plurinacional e laico. É uma república democrática com o poder que vem do povo, onde sua vontade é pedra basilar da autoridade que será exercida pelas formas previstas na Constituição. Em seu art. $1^{\circ}$ é estabelecido que os recursos naturais não renováveis do território equatoriano são patrimônio do Estado e são inalienáveis, irrenunciáveis e imprescritíveis ${ }^{19}$.

A Constituição do Equador em seu preâmbulo estabelece como objetivo a criação de uma nova forma de convivência cidadã, com bases na diversidade e na harmonia com a natureza para alcançar o buen vivir ${ }^{20}$. E uma importante inovação está prevista a partir do capítulo sétimo onde é prevista a natureza como sujeito de direito ${ }^{21}$ e a responsabilidade do Estado em promover políticas públicas de prevenção e restrição de atividades que possam prejudicar de forma permanente o ecossistema ${ }^{22}$.

O reconhecimento da Natureza como sujeito de direito tem como objetivo a busca pelo equilíbrio entre as necessidades dos seres humanos com a natureza, dando destaque e proteção no texto constitucional. Portanto, a natureza não se restringe apenas ao direito do homem a ter um ambiente saudável, como é previsto na maioria das constituições ao redor do mundo ${ }^{23}$.

Ambas as constituições trazem para o debate importante modificação para a formação do Estado: o pluralismo. O sistema plurijurídico tem como característica principal a

19 Art. 1. El Ecuador es un Estado constitucional de derechos y justicia, social, democrático, soberano, independiente, unitario, intercultural, plurinacional y laico. Se organiza en forma de república y se gobierna de manera descentralizada. La soberanía radica en el pueblo, cuya voluntad es el fundamento de la autoridad, y se ejerce a través de los órganos del poder público y de las formas de participación directa previstas en la Constitución. Los recursos naturales no renovables del territorio del Estado pertenecen a su patrimonio inalienable, irrenunciable e imprescriptible.

20 "Decidimos construir: Una nueva forma de convivencia ciudadana, en diversidad y armonía con la naturaleza, para alcanzar el buen vivir, el sumak kawsay; Una sociedad que respeta, en todas sus dimensiones, la dignidad de las personas y las colectividades (...)".

${ }^{21}$ Art. 71. La naturaleza o Pacha Mama, donde se reproduce y realiza la vida, tiene derecho a que se respete integralmente su existencia y el mantenimiento y regeneración de sus ciclos vitales, estructura, funciones y procesos evolutivos.

${ }^{22}$ Art. 73. EI Estado aplicará medidas de precaución y restricción para las actividades que puedan conducir a la extinción de especies, la destrucción de ecosistemas o la alteración permanente de los ciclos naturales.

${ }^{23}$ Nos dizeres de Frei Beto, "Para a sociedade capitalista, a natureza é objeto de propriedade e temos o direito de explorá-la e até destruí-la em função de nossas ambições. O capitalismo se norteia pelo paradigma riquezapobreza, enquanto o sumak kawsay rompe esse dualismo para introduzir a de sociabilidade e de sustentabilidade, bases fundamentais de um projeto civilizatório. Fora disso, caminharemos para a barbárie." (disponível em http://amaivos.uol.com.br/amaivos2015/?pg=noticias\&cod_canal=53\&cod_noticia=17035, acesso em 08 de dezembro de 2018). 
coexistência de diversos sistemas jurídicos, de formas de organização econômica que possibilitam em um novo olhar democrático e construção de espaços de convivências e diálogos de diversas formas de ver, sentir, compreender o mundo (MAGALHÃES, 2012, p. 85). Por conseguinte,

\begin{abstract}
A ideia de Estado Plurinacional pode superar as bases uniformizadoras e intolerantes do Estado Nacional, onde todos os grupos sociais devem se conformar aos valores determinados na constituição nacional em termos de direito de família, direito de propriedade e sistema econômico, entre outros aspectos importantes da vida social. A grande revolução do Estado Plurinacional é o fato de que este Estado constitucional, democrático participativo e dialógico, pode finalmente romper com as bases teóricas e sociais do Estado Nacional constitucional e democrático representativo (pouco democrático e nada representativo dos grupos não uniformizados), uniformizador de valores e, logo, radicalmente excludente (MAGALHÃES; WEIL, 2010, p. 17-18).
\end{abstract}

O pluralismo vem com papel central na refundação do Estado, estimulando o reconhecimento da diversidade existente dentro das nações e para tanto é preciso ações dos Estados para a concretização da inclusão de todos. Dessa maneira, o pluralismo deve ser compreendido como uma obrigação dos Estados contemporâneos, pois significa a inclusão das minorias, conjunto da população historicamente excluída do poder e das políticas hegemônicas.

Os modelos de Estados apresentados pelo Equador e Bolívia são propostas de convivência harmônica em sociedade, e, como destaca Boaventura de Souza Santos (2010) são laboratórios a céu aberto onde o Estado poderá ser ressignificado no plano efetivo do $\operatorname{poder}^{24}$. O Pluralismo apresentado por estes Estados passa a ser reconhecido como fundamento constitucional e influenciam diretamente a organização do Estado por meio da participação social nas instituições estatais.

Verifica-se que o Buen Vivir é mais que declaração constitucional estabelecida nas constituições bolivianas e equatorianas, deve ser interpretado como uma oportunidade de construir coletivamente um novo regime de desenvolvimento e de concepção de vida. É um caminho qualitativo para um desenvolvimento integrado e plural. Não deve ser reduzido apenas a um conjunto de artigos e apenas a região andina. O buen vivir visa à promoção de uma vida harmoniosa entre os seres humanos e natureza por meio da construção de uma

\footnotetext{
${ }^{24}$ É o que o Boaventura define como Estado experimental, pois "é o desafio mais radical do Estado moderno, cujas as instituições e leis, e sobretudo as constituições, estão aparentemente inscritas em pedra" (SANTOS, 2010, p. 111).
} 
economia solidária e garantias de direitos sociais, econômicos e ambientais (ACOSTA, 2011, p. 193-194).

\section{Considerações finais}

O progresso, sob o prisma do capitalismo, tem como objetivo um governo mundial baseado no fundamentalismo de mercado, onde os Estados e a sociedade serão apenas subalternos. Por meio de uma instrumentalidade neoliberal, é imposto um conhecimento universalizante, aplicado e aprimorado por organizações internacionais e grandes empresas, onde o capital passa a ser considerado o único caminho para se obter a satisfação humana. É neste rumo que a cultura do consumo é imposta e naturalizada.

A imposição colonial de um modelo de organização social, econômica e política trouxe consigo seu fundamentos filosóficos de compreensão da vida e do ser humanos, encobrindo ou destruindo a imensa diversidade de percepçoes, a grande diversidade epistemológica presente na América e em todo o mundo. O sistema mundo moderno colonial é na sua essência hegemônico e uniformizado, subalternizando o que está fora de suas fronteiras epistemológicas. Entretanto a América Latina, nos seus processos de resistencia e luta social, trouxe para o campo do Direito uma revolução epistemológica. No momento em que as instituições e teorias jurídicas modernas são invadidas por compreensões que fogem de sua finalidade primeira, temos a oportunidade de salvar o direito para além do sistema mundo moderno, sistema que o criou. Ao se aprisionar o Direito aos seus principios modernos podemos assistir a obsolescenia deste com a crise final da modernidade que está em curso.

O movimento do novo constitucionalismo latino americanos pode significar esta tranformação do Direito, de maneira que este possa sobreviver à superação do sistema mundo colonial moderno. O novo constitucionalismo pode possibilitar uma revolução no Direito, baseada na democracia dialógica popular, comunitária e consensual, direito da natureza, e em uma economia igualitária, socialmente e culturalmente diversa.

O Buen Vivir, conforme apresentado, visa a fusão pluriversal dos conhecimentos. Apresenta, assim, uma visão crítica da globalização e seu plano de desenvolvimento. Ao expor os limites do progresso, crescimento, desenvolvimento e bem-estar abre caminho para a discussão sobre como é visto o individualismo, o papel dos Estados e organismos internacionais em relação a um processo de desenvolvimento local que gera menos desigualdades. É um projeto que visa contribuir para afastar os globalismos localizados apresentado por Boaventura. 
A ética do Buen Vivir permite a formulação e implementação de políticas públicas que unam esforços que vão desde o poder local ao poder global com o objetivo de diminuir as desigualdades e assimetrias de poder do mercado na economia capitalista. Portanto, é um projeto resistente e alternativo. É o construir um outro mundo sem se preocupar de acbar com o anterior mas simplesmente de superá-lo. A força deve ser usada na construção do novo, do radicalmente novo e não na destruição do antigo.

É urgente pensar, conversar, sentir e discutir amplamente a relação do buen vivir, plurinacionalidade, interculturalidade e decolonialidade como fundamento de um outro sistema mundo, horizontal, plural, diverso, onde a complementaridade no permita ampliar a percepção da vida.

\section{Referências bibliográficas}

ACOSTA, Alberto. O Bem Viver: uma oportunidade para imaginar outros mundos. São Paulo: Autonomia Literária, 2016.

ACOSTA, Alberto. El Buen Vivir en el camino del post-desarrollo. Una lectura desde la constitución de Montecristi. In: Policy Paper, Fundación Friedrich Ebert, 2010.

ACOSTA, Alberto. Sólo imaginando otro mundos. In: FARAH, Ivonne; VASAPOLLO, Luciano (Coordinadores). Vivir Bien ¿Paradigma no capitalista? La Paz: Bolivia, Universidad Mayor de San Andrés (CIDESUMSA), 2011.

ACOSTA, Alberto; GUDYNAS, Eduardo. El buen vivir mas allá del desarrollo. In: Quehacer, 2011. Disponível em:

http://www.dhl.hegoa.ehu.es/ficheros/0000/0709/4.El_buen_vivir_mas_all\%C3\%A1_del_des arrollo.pdf, acesso em 29 de novembro de 2018.

ALBÁN A., Adolfo; ROSERO, José R. Colonialidad de la naturaleza: ¿imposición tecnológica y usurpación epistêmica? Interculturalidad, desarrollo y re-existencia. In:

Nómadas, $n^{\circ} 45$, octubre, 2016, p. 27-41.

CLAVERO, Bartolomé. Estado Plurinacional: aproximação e um novo paradigma constitucional americano. In: BALDI, César Augusto (coord.). Aprender desde o Sul: novas constitucionalidades, pluralismo jurídico e plurinacionalidade. Aprendendo desde o Sul. Belo Horizonte: Fórum, 2015, p. 111-131. 
DUSSEL, Enrique. 1492 EI Encubrimento del Outro: hacia el origen del "mito" de la modernidade. La Paz: Plural, 1994.

DUSSEL, Enrique.; IBARRA-COLADO, Eduardo. Globalization, Organization and the Ethics of Liberation. In: Organization, v.13 n. 4, p. 489-508, 2006.

ESCOBAR, A. Latin America at a Crossroads: Alternative Modernizations, Post-liberalism, or Post-development?. In: Cultural Studies, v. 24, n. 1, p. 1-65, jan. 2010.

ESTERMANN, J. Ecosofía andina: un paradigma alternativo de convivencia cósmica y de vivir bien. In: FAIA, v. II, n. IX-X, p. 1-21, 2013

GUDYNAS, Eduardo. Buen vivir: Germinando alternativas al desarrolo. In: America Latina en Movimiento, ALAI, no 462, p. 1-20, fevereiro de 2011. Disponível em:

http://www.flacsoandes.edu.ec/web/imagesFTP/1317332248.RFLACSO_2011_Gudynas.pdf, acesso em 29 de novembro de 2018.

HOBSBAWN, Eric. Nações e Nacionalismo desde 1780. São Paulo: Editora Paz e Terra, 1991.

LANDER, Edgardo. Ciencias sociales: saberes coloniales y eurocéntrico. In: LANDER, Edgardo (cood). La colonialidad del saber: eurocentrismo y ciencias sociales. Perspectivas latinoamericanas. Buenos Aires: CLACSO. 2000.

LITTLE, Paul E. Etnodesenvolvimento local: autonomia cultural na era do neoliberalismo global. In: Tellus, ano 2, n. 3, p. 33-52, out. 2002.

MAGALHÃES, José Luiz Quadros de. Estado Plurinacional e Direito Internacional. Curitiba: Juruá Editora, 2012.

MAGAlHÃeS, José Luiz Quadros de. O Estado Plurinacional Na América Latina. Conteúdo Jurídico, Brasília-DF: 27 mar. 2009. Disponível em: http://www.conteudojuridico.com.br/?colunas\&colunista=50\&ver=257, acesso em $07 \mathrm{de}$ dezembro de 2018.

MAGALHÃES, José Luiz Quadros de; WEIL, Henrique. Bioética no Estado de Direito Plurinacional. In: Revista Direitos Culturais, $n^{\circ}$ 8, v. 5, 2010. 
MAMANI, F. H.. Buen Vivir/Vivir Bien. Filosofia, políticas, estrategias y experiencias regionales andinas. CAOI, 2010.

MELO, Milena Petters; BURCKHART, Thiago. A Constituição Equatoriana de 2008: uma nova concepção de estado e pluralismo. In: Trayectorias Humanas Transcontinentales, $\mathrm{n}^{\mathrm{o}}$ 3 , setembro de 2018 , p. 7-21.

MELO, Milena Petters. O patrimônio comum do constitucionalismo contemporâneo e a virada biocêntrica do 'novo' constitucionalismo latino-americano. In: Revista Novos Estudos Jurídicos, Itajaí, v.18, n. 1, jan.-abr. 2013, p. 74-84.

MIGNOLO, W. El pensamiento dês-colonial, desprendimiento y apertura: un manifesto. Tristes Trópicos, 2005.

MONTESQUIEU, C. de D. B. de. O espírito das Leis: as formas de governo, a federação, a divisão dos poderes, presidencialismo versus parlamentarismo. $3^{\mathrm{a}}$ Ed. São Paulo: Saraiva, 1994.

ROBL FILHO, I. N. Conselho Nacional de Justiça: Estado democrático de direito e accountability. São Paulo : Saraiva, 2013.

SANTOS, Boaventura de Souza. Por uma concepção multicultural dos Direitos Humanos. In: Revista Crítica de Ciências Sociais, nº 48, junho de 1997, págs. 11-32.

SANTOS, Boaventura de Souza. La globalización del Derecho: los nuevos caminos de la regulación y la emancipación. Bogotá, Instituto Latinoamericano de Servicios Legales Alternativos, ILSA, 1998.

SANTOS, Boaventura de Souza. Para uma concepção multicultural dos Direitos Humanos. In: Contexto Internacional. Rio de Janeiro, no 1, vol. 23, jan./jun. 2001.

SANTOS, Boaventura de Souza. Globalizations. Theory Culture Society, n. 23, 2006.

SANTOS, Boaventura de Souza; MENESES. Epistemologia do Sul. Coimbra: Editora Almedina, 2009.

SANTOS, Boaventura de Souza. Refundación del Estado en América Latina: perspectivas desde una epistemología del Sul. Lima: RELAJU, 2010. 
SANTOS, Milton. A natureza do espaço: Técnica e Tempo. Razão e Emoção. São Paulo: EdUsp, 2014.

SEN, Amartya. Desenvolvimento como liberdade. São Paulo: Companhia das Letras, 2010.

SILVA, Heleno Florindo da. Teoria do Estado Plurinacional: o novo constitucionalismo Latino-americano e os direitos humanos. Curitiba: Juruá Editora, 2014.

TODOROV, Tzvetan. A conquista da América: a questão do outro. 4. ed. São Paulo: WMF Martins Fontes, 2010.

VICIANO, Roberto. MARTÍNEZ, Rubén. Corte Constitucional de Ecuador para el período de transición. El Nuevo Constitucionalismo em America Latina. 1.ed, Quito, 2010. Disponível em https://mestrado.direito.ufg.br/up/14/o/34272355-Nuevo-

Constitucionalismoen-America-Latina.pdf?1352144011, acesso em 29 de novembro de 2018.

WALSH, Catherine. Interculturalidad, plurinacionalidad y decolonialidad: las insurgencias político-epistémicas de refundar el Estado. In: Tabula Rasa, n. 9, julio-diciembre, 2008, p. 131- 152. Universidad Colegio Mayor de Cundinamarca Bogotá, Colombia.

WOLKMER, Antônio Carlos; WOLKMER, Maria de Fátima Schumacher; AUGUSTIN, Sérgio. O 'novo' Direito à Água no constitucionalismo da América Latina. In: Revista INTERthesis, v. 9, 2012, p. 51-69. 